\title{
Personal and Financial Risk Typologies Among Women Who Engage in Sex Work in Mongolia: A Latent Class Analysis
}

\author{
Reid Offringa $^{1} \cdot$ Laura Cordisco Tsai $^{2} \cdot$ Toivgoo Aira $^{3} \cdot$ Marion Riedel $^{1} \cdot$ \\ Susan S. Witte ${ }^{1}$
}

Received: 10 June 2015 / Revised: 12 April 2016/ Accepted: 20 July 2016/ Published online: 29 July 2016

(c) Springer Science+Business Media New York 2016

\begin{abstract}
Women engaged in sex work bear a disproportionate burden of HIV infection worldwide, particularly in low- to middle-income countries. Stakeholders interested in promoting prevention and treatment programs are challenged to efficiently and effectively target heterogeneous groups of women. This problem is particularly difficult because it is nearly impossible to know how those groups are composed a priori. Although grouping based on individual variables (e.g., age or place of solicitation) can describe a sample of women engaged in sex work, selecting these variables requires a strong intuitive understanding of the population. Furthermore, this approach is difficult to quantify and has the potential to reinforce preconceived notions, rather than generate new information. We aimed to investigate groupings of women engaged in sex work. The data were collected from a sample of 204 women who were referred to an HIV prevention intervention in Ulaanbaatar, Mongolia. Latent class analysis was used to create subgroups of women engaged in sex work, based on personal and financial risk factors. This analysis found three latent classes, representing unique response pattern profiles of personal and financial risk. The current study approached typology research in a novel, more empirical way and provided a description of different subgroups, which may respond differently to HIV risk interventions.
\end{abstract}

Keywords Sex work $\cdot$ HIV prevention $\cdot$ Latent class analysis

Laura Cordisco Tsai

lcordisc@gmu.edu

1 Columbia University School of Social Work, New York, NY, USA

2 Department of Social Work, George Mason University, 10340 Democracy Lane, Fairfax, VA 22030, USA

3 Wellspring NGO, Ulaanbaatar, Mongolia

\section{Introduction}

Women who engage in sex work face a disproportionate risk for HIV, burden of HIV, and lack of access to HIV services around the world (Beyreret al., 2015). While the organization and facilitation of sex work is illegal in Mongolia, it is still a common industry fueled in part by a challenging economy and a lack of employment options. UNICEF (2006) estimated that 4000 people, primarily women, were engaged in sex work in the capital city of Ulaanbaatar. This estimate would mean that roughly. $1 \%$ of the population is engaged in sex work, which is consistent with other parts of Asia (Kerrigan et al., 2013). However, the recent influx of mining and investment opportunities, coupled with growth in international tourism in Mongolia, may have contributed to recent growth in the sex work industry (Carlson et al., 2014; Hagan \& Dulmaa, 2007). As a country in economic and political transition, Mongolia is considered highly vulnerable to the spread of HIV/AIDS. STI prevalence is high and increasing among women engaged in sex work in Mongolia (Baral et al., 2013). For instance, a study among 179 women in sex work in three urban centers found that $67 \%$ had one or more STIs (Hagan \& Dulmaa, 2007). In addition to heightened risk for STIs, women in sex work experience a wide range of risk factors, including alcohol use, depression, physical and sexual violence, and financial vulnerability - all of which have been shown to increase risk for HIV infection (Baral et al., 2012; Deering et al., 2014; Witte, Batsukh, \& Chang, 2010).

\section{Alcohol Use}

Studies with sex workers from low- and middle-income countries have reported consistent and positive associations between unsafe sexual behaviors and alcohol use (Li, Li, \& Stanton, 2010; Shuper et al., 2010). Systematic reviews have found a positive association between alcohol use and both the risk of HIV (Kalichman, Simbayi, Kaufman, Cain, \& Jooste, 2007) and actual HIV infection 
(Fisher, Bang, \& Kapida, 2007). The use of alcohol, particularly vodka, is widely prevalent in Mongolia. Although men tend to drink alcohol at higher rates than women among the larger population in Mongolia (WHO, 2011), a study with a sample of 45 women in sex work found that 85 percent reported hazardous or harmful alcohol use. Women engaged in sex work in Mongolia have described using alcohol as a disinhibitor prior to engagement in sex work. Some have argued that alcohol is a way to cope with the internalized and external stigma related to sex work (Witte et al., 2010).

\section{Depression}

Prior research has also revealed high rates of depression among individuals engaged in sex work (Gu et al., 2010; Nemoto, Bodeker, \& Iwamoto, 2011) and indications that depression is associated with HIV risk. A systematic review pertaining to the psychological health of women working in sex work globally reported the prevalence of depression at $62.4 \%$. This systematic review also found a significant association between depression and sexual risk-taking in four out of five studies included in the review (Yuen et al., 2016). The relationship between depression and HIV risk is more typically mediated by other HIV risk behaviors, including alcohol use. A recent study in China of women engaged in sex work found that alcohol use independently contributed to depression among these women, above and beyond partner violence and illicit drug use (Zhang et al., 2014). These findings raise concerns regarding the directional nature of the relationship (e.g., Is alcohol used for coping with depression or does depression follow increased alcohol use?) Very few studies have directly examined the mental health of women in Mongolia, including those engaged in sex work. One recent study with women engaged in sex work in Ulaanbaatar found that $60.4 \%$ were at high risk for depression. Furthermore, variables such as harmful alcohol use, sexual violence, lack of social support, and perceived social stigma were identified as risk factors for depression among sex workers in Mongolia (Carlson et al., 2016).

\section{Violence}

Women who engage in sex work are at heightened risk for experiencing violence from paying partners, managers, police, and intimate partners (Karandikar \& Prospero, 2010; Nixon, Tutty, Downe, Gorkoff, \& Ursel, 2002; Open Society Institute, 2009; Rhodes, Simic, Baros, Platt, \& Zikic, 2008). Rates of violence against women engaged in sex work by an intimate partner are more than double the rates for women in the general population (Oyunbileg, Sumberzul, Udval, Wang, \& Janes, 2009; Parcesepe et al., 2015). Mongolian women engaged in sex work also report high rates of violence at the hands of paying partners (Carlson et al., 2012, 2014; Parcesepe et al., 2015). Experiences of violence by either intimate or paying partners have been found to be associated with greater risk for HIV infection among women in sex work in Mongolia (Parcesepe et al., 2015). In Mongolia, at least one prevention intervention that took these risk factors into account effectively reduced HIV/STI risk, harmful alcohol use, and exposure to paying partner violence among women engaged in sex work(Carlson et al., 2012; Witte etal., 2011).

\section{Financial Challenges}

In addition to these personal risk factors, financial vulnerability has been linked to women's decisions to engage in sex work and the risks they face as sex workers. McCarthy, Benoit, and Jansson (2014) examined the competing literature regarding what may lead individuals to sex work, finding that growing up in poverty and as an adult having lower levels of education and fewer occupational experiences led many to engage in sex work. Financial challenges for women engaged in street-based sex work include, among others, lack of control over working conditions and pricing, outstanding debt, disruptions in income due to police raids, and seasonal variability in sex work income (Reed, Gupta, Biradavlou, Devireddy, \& Blankenship, 2010), which is particularly concerning in the Mongolian context given the severe winter weather conditions. The relationship between financial vulnerability and HIV risk among women engaged in sex work has long been established. Household financial instability has been linked to increased HIV risk behaviors (Aidala, Cross, Stall, Harre, \& Sumartojo, 2005). Researchers have suggested that a compromised financial situation may inhibit a woman's ability to negotiate safe sex practices with paying partners out of fear of losing earnings (Odek et al., 2009; Sherman et al., 2010; Stratford, Mizuno, Williams, Courtenay-Quirk, \& O'Leary 2008). Additionally, women engaged in sex work who report having debt are more likely to also report STI symptoms and heightened exposure to HIV risk through unprotected sex with occasional clients and anal sex (Reed et al., 2010; van Griensven, Limanonda, Chongwatana, Tirasawat, \& Coutinho, 1995). Many prevention interventions that take these risk factors into account have effectively reduced HIV/STI risk and other risk factors among women engaged in sex work in resource-poor countries (Shahmanesh, Patel, Mabey, \& Cowan, 2008).

\section{Typologies}

There is a growing literature on sex work typologies, though few proposed typologies are rigorously tested. In an earlier effort, Harcourt and Donovan (2005) used their expertise to create risk categories (low, medium, high). They argued that such a categorization could be used as a checklist for targeted intervention, but did not provide empirical evidence for such categories, beyond their expertise. Furthermore, some have criticized previous typology efforts (e.g., Weitzer, 2005), particularly because they reinforce preexisting notions that can frame all of sex work as inherently violent.

Puradiredja and Coast (2012) found that women engaged in sex work in rural locations in Indonesia were significantly less likely to use condoms, compared to women working in sex work in urban locations. By comparison, Yang, Latkin, Luan, and Nelson (2010) found that both personal factors and location predicted 
consistent condom use for women in sex work within lower social ranks. Notably, personal factors did not relate to condom use within middle and upper social ranks. This strong relationship between location and condom use may have been due to managers at certain locations, who enforced strict condom policies. Importantly, most studies have not tried to identify risk groups based on the cooccurrence of several variables.

These results typify the risk typology research for women in sex work, with the findings largely built around social class, place of solicitation, and specific moderators of those variables. In fact, some have argued that risk typology research places too much emphasis on the place of solicitation (e.g., Harcourt \& Donovan, 2005) and that these do not necessarily capture different levels of risk (Buzdugan, Halli, \& Cowan, 2009; Weitzer, 2005). In addition, Weitzer has criticized previous studies for choosing best-case and worst-case scenarios in order to prove a point, while others have not adequately quantified important variables, such as violence. Of these attempts to classify risk, few have been rigorously tested and none have benefitted from examining financial and personal risk typologies.

In the current study, we have expanded upon the research examining sex work typologies. We hypothesized that women who engage in sex work can be classified into latent risk categories. These categories are latent because they cannot be directly observed by any given variable; instead, their existence is inferred by the way observed variables co-occur. A similar technique has been used previously to categorize people who use drugs. Lynskey et al. (2006) reported evidence for a distinction between polydrug users, opioid users, alcohol-only users, and marijuana users. Defining such classes among women engaged in sex work will certainly helpour understanding of risk within the population, which can help inform future interventions.

The current study utilized latent class analysis (LCA) and aimed to identify groupings of women engaged in sex work, based on both personal and financial risk variables. We hypothesized that each of these latent classes significantly differed from each other. This hypothesis was tested by comparing the resulting classes via variables that were not included in the LCA. To our knowledge, no such study has yet examined these sex worker typologies using this technique. Employing an empirical approach to identify classes should inform targeted interventions that may address dual issues of personal and financial risk.

\section{Method}

\section{Participants}

This study used baseline data from a sample of women screened eligible to participate in a two-arm, randomized clinical trial examining sexual risk reduction among 204 women engaged in streetbased sex work in Ulaanbaatar, Mongolia. Detailed study methods and procedures for the main trial are described elsewhere (Tsai et al., 2015; Witte et al., 2015). Outcomes of the parent study included reductions in sexual risk behaviors (as measured by self-reported number of unprotected acts of vaginal intercourse) and in proportion of income from sex work (as measured by income from sex work in the past 90 days divided by all income).

Women were recruited from 2009 to 2011 in Ulaanbaatar, Mongolia, using a targeted sampling methodology. The study team first developed a list of street-based sex work venues identified by participants in prior studies (Witte et al., 2015) and the Community Advisory Board. The study team conducted multiple observations per site, recording the number of women seen soliciting at each site. These observations were then used to develop a proportional sampling strategy, as recommended by Peterson et al. (2008). A targeted sampling methodology was used in order to reach a more diverse and representative sample of women engaged in sex work and to improve the generalizability of findings. Eligible women were at least 18 years of age and reported having engaged in vaginal or anal sexual intercourse in the past 90 days in exchange for money, alcohol, or other goods. In addition, they reported having engaged in unprotected vaginal or anal sex in the past 90 days with a paying sexual partner and reported an interest in learning about alternative ways in which to earn income. Following screening, a total of 204 eligible women completed an interviewer-administered baseline assessment. Interviewers were trained, Masters level research assistants, and the assessment responses were entered into a computer-based program. Informed consent was obtained from all participants, and the trial was approved by the Institutional Review Board at Columbia University and the National University of Mongolia.

\section{Measures}

The baseline survey included questions on sociodemographic background (age, years in sex work, age when initiated sex work, education, marital status, has intimate partner, and number of sex work partners) and 11 factors associated with risk: five associated with personal or sexual risk-taking and six associated with financial vulnerability. Three personal risk variables associated with sexual HIV transmission were harmful alcohol use (assessed using the Alcohol Use Disorders Identification Test [AUDIT]) (Cronbach's $\alpha=.88$ ) (Saunders, Aasland, Babor, de la Fuente, \& Grant, 1993), experiences with violence [assessed using a 5-question modified Conflict Tactics Scale (CTS)] (Cronbach's alpha ranged from .79 to .95) (Straus, Hamby, Boney-McCoy, \& Sugarman, 1996), and symptoms of depression [assessed using the Brief Symptom Inventory depression subscale (BSI)] (Cronbach's $\alpha=.85$ ) (Derogatis, 1993). In addition, we quantified sexual risk with two variables: number of times women engaged in unprotected vaginal sex with paying partners and how frequently women were offered more money for sex without a condom. Participants provided self-reported data on the number of paying partners and the number of times they had engaged in unprotected vaginal and anal sex with paying partners in the prior 90 days. 
Finally, we assessed financial risk variables including: whether sex work was the participant's primary source of income; participant reported number of dependents; whether participants' household had more than one income; whether the participant was in debt; whether participant had savings; and participants' total earnings per month. For continuous variables [harmful alcohol use (AUDIT), depression score (BSI), number of unprotected vaginal sex acts with a paying partner, and household income], we calculated the median value and used this value to create a categorical variable. Therefore, all continuous variables included in the LCA indicated whether participants were above or below the median value of this dataset. Categorical variables either were used in their raw format (e.g., yes/no) or were simplified in order to reflect the questions listed above.

Variables were dichotomized in order to simplify interpretation and reduce potential complications from non-normally distributed scales. Although not all scales were non-normally distributed, all scales were dichotomized in order to provide a homogenous, easy interpretation. Furthermore, dichotomized variables may enhance generalizability of the latent class analysis. For example, scales and methods differ across studies and we wanted to construct a simple, more externally valid risk classification for both clinicians and researchers.

In a second stage of analysis (below), we sought to further examine distinctions between identified classes and their relevance for informing future prevention efforts. For this, we selected some variables included in the original LCA, but also some which represented traditional moderators in HIV prevention intervention: age, length of time in sex work, age at which began sex work, severe sexual violence (had the participant ever experienced rape as an adult), having an intimate partner, marital status, income from sex work, and total income. We also selected some mediators, including level of family social support, as measured by the Multidimensional Scale of Perceived Social Support (Cronbach's $\alpha=.84$ ) (Zimet, Dahlem, Zimet \& Farley, 1988) and intention to use condoms. To measure family social support, we asked participants to rate their level of agreement (very strongly disagree to very strongly agree) with 12 statements pertaining to family and social support. Examples of these statements include: "There is a special person who is around when I am in need" and "I can talk about my problems with my family." To measure intention to use condoms, we asked participants to note their level of agreement (disagree strongly to agree strongly) with two statements: "I plan to use male condoms if I have sex in the next 3 months with my trust partner" and "I plan to use male condoms if I have sex in the next 3 months with my paying partners." These items were summed into a continuous measure of social support.

\section{Data Analysis}

LCA is an analytic tool used to identify homogeneous, mutually exclusive groups, or classes that exist within a heterogeneous population (Clogg, 1995; McCutcheon, 1987). Analysis seeks to identify the underlying patterns (groupings or classes) of behavior based on women's observed responses to questions related to 11 risk variables. The variables were selected based on the empirical literature describing individual and structural risks faced by women engaged in sex work. To study the underlying structure of these data, a series of LCA models were fit and examined.

As noted above, in a second stage of analysis, we sought to further examine distinctions between identified classes and their relevance for informing future prevention efforts. Variables not included in the LCA, but which empirically characterize other forms of risk, including moderators or mediators of prevention efforts, were tested across groups to examine whether they were similar or different: Could they demonstrate distinctions across groups for additional, related risk factors? We hypothesized that each of these latent classes significantly differed from each other, and that we could demonstrate this based on some untransformed variables in the analysis and related variables that were not used to calculate the latent classes.

Consistent with previous applications of these LCA methods, dichotomous variable specifications were selected for the final analysis to enhance the interpretability of findings. As described above, risk-based cut-points were carefully selected. Using SAS (Release 9.1. Cary, NC: SAS Institute Inc.), the PROC LCA command procedure was used to estimate model parameters (Lanza, Collins, Lemmon, \& Schafer, 2007). PROC LCA produces maximum likelihood estimates for parameters using the EM algorithm. Missing data on individual survey items were handled within the EM algorithm and were assumed to be missing at random (Lanza et al., 2007).

\section{Results}

Table 1 shows the sociodemographic characteristics and behavioral risks of study participants. On average, participants were 35.6 years old, had exchanged sex for money for the past 6.2 years, and had an average of 39.5 unprotected sex acts for pay over the last 3 months. They were most frequently divorced, widowed, or separated and had completed a high school education.

To determine classes, we first generated several different models with a range of latent classes. Model fit was determined by comparing Akaike information criteria (AIC) to Bayesian information criteria(BIC) values for models with different numbers of classes. In addition, we used the parametric bootstrapped likelihood ratio test (PBL RT), which is an absolute measure of model fit. As can be seen in Fig. 1, the three-class solution represented an optimal compromise between the AIC and BIC. In addition, the PBLRT indicated that the three-class solution fit the data significantly better than the twoclass solution $(p=.01)$. By contrast, the three-class solution did not explain significantly more variance, compared to the four-class solution $(p=.11)$. This indicated that the three-class solution was more desirable, because it explained the same amount of variance with a more parsimonious model. Figure 1 illustrates the AIC, BIC, and PBLRT. Table 2 shows the G2, degrees of freedom, AIC, BIC, and 
Table 1 Sociodemographic characteristics of participants by latent class

\begin{tabular}{|c|c|c|c|}
\hline & $\begin{array}{l}\text { Low financial risk } \\
n=42\end{array}$ & $\begin{array}{l}\text { High risk overall } \\
n=82\end{array}$ & $\begin{array}{l}\text { Low personal risk } \\
n=80\end{array}$ \\
\hline \multicolumn{4}{|l|}{ Mean $(S D)$} \\
\hline Age (in years) & $33.48(9.81)$ & $36.44(9.09)$ & $35.74(9.33)$ \\
\hline Age initiated sex work (in years) & $27.60(8.73)$ & $29.08(8.35)$ & $30.05(8.53)$ \\
\hline Years of sex work (SW) & $5.75(6.34)$ & $7.07(5.36)$ & $5.57(4.66)$ \\
\hline No. of dependents & $.74(0.83)$ & $1.53(1.27)$ & $1.64(1.35)$ \\
\hline No. paying partners ${ }^{\mathrm{a}}$ & $116.45(83.80)$ & $122.23(128.61)$ & $48.06(62.17)$ \\
\hline No. unprotected sex acts ${ }^{\mathrm{a}}$ & $64.69(65.20)$ & $59.27(74.56)$ & $5.23(9.36)$ \\
\hline Alcohol use (AUDIT) & $12.74(8.20)$ & $23.75(8.09)$ & $12.83(9.22)$ \\
\hline Depression (BSI) & $7.38(5.30)$ & $11.01(5.51)$ & $6.94(5.45)$ \\
\hline Overall family support & $58.40(12.52)$ & $47.04(15.64)$ & $53.78(16.13)$ \\
\hline Total monthly income ( $100 \mathrm{k}$ tugriks) & $887(790)$ & $498(355)$ & $720(493)$ \\
\hline Monthly SW income & $720(768)$ & $388(355)$ & $373(504)$ \\
\hline \multicolumn{4}{|l|}{ Percent of latent class } \\
\hline $\mathrm{SW}$ as primary income & $88.1 \%$ & $95.1 \%$ & $80.0 \%$ \\
\hline Has savings & $47.6 \%$ & $4.9 \%$ & $11.3 \%$ \\
\hline Has debt & $21.4 \%$ & $73.2 \%$ & $50.0 \%$ \\
\hline Divorced, widowed, or separated & $33.3 \%$ & $64.6 \%$ & $50.0 \%$ \\
\hline Has intimate partner & $61.9 \%$ & $36.6 \%$ & $62.5 \%$ \\
\hline Primary income earner & $66.7 \%$ & $84.1 \%$ & $80.0 \%$ \\
\hline Household has more than one income & $33.3 \%$ & $15.9 \%$ & $20.0 \%$ \\
\hline \multicolumn{4}{|l|}{ Education } \\
\hline Less than secondary & $11.9 \%$ & $8.5 \%$ & $5.0 \%$ \\
\hline Secondary & $71.4 \%$ & $70.7 \%$ & $81.3 \%$ \\
\hline More than secondary & $16.7 \%$ & $20.7 \%$ & $13.8 \%$ \\
\hline
\end{tabular}

Categorical variables are summarized with a percent, while continuous variables are summarized with mean (SD). Variables tagged with $\left({ }^{\mathrm{a}}\right)$ refer to the past 3 months. Note that, in the sample, AUDIT ranges from 0 to 38; BSI ranges from 0 to 24; total monthly income ranges from 3000 to 4,000,000 Mongolian tugriks

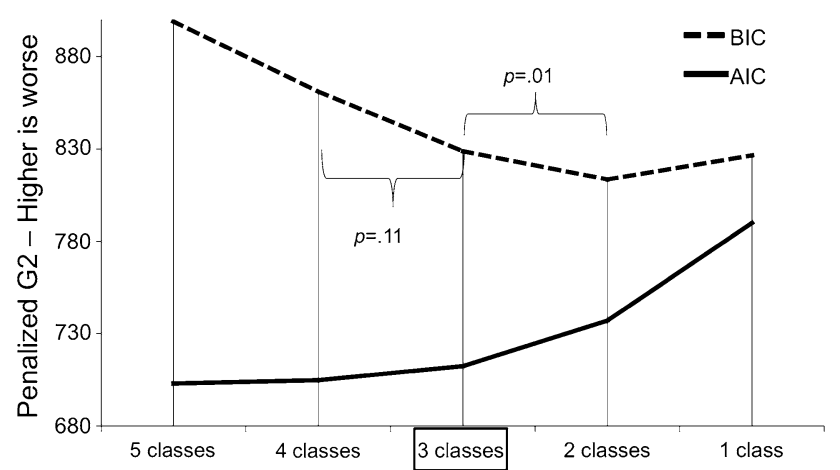

Fig. 1 Fit metrics indicate three latent classes as optimal

parametric bootstrapped likelihood ratio test (PBLRT) for each potential class solution.

\section{Three Latent Risk Classes}

The model fit criteria listed above uniformly indicated that three latent classes did the best job of explaining our data. Using item response probabilities, we interpreted the three classes as shown in Table 3 and Fig. 2 and articulated below:

1. Class 1 demonstrated mixed personal risk with low financial risk $(n=42 ; 20.6 \%)$. The mixed personal risk with low financial risk group exhibited a lower probability of having abovemedian AUDIT scores, experiences with violence and depression scores, but a higher probability of unprotected sex acts with paying partners. Interestingly, this group did not exhibit good group separation for AUDIT scores, experiences of violence or depression (BSI), but still exhibited a high probability of abovemedian scores for unprotected vaginal sex with paying partners and being offered more money for unprotected sex. Importantly, this risk group exhibited a significantly lower probability of being the only earner for the household, a lower risk of reporting debt or no savings, and was more likely to report fewer dependents. Most importantly, the mixed personal risk with low financial risk group was less likely to report below-median incomes, compared to other latent classes.

2. Class 2 was characterized by high personal risk with high financial risk $(n=82 ; 40.2 \%)$. Separation for high personal risk was 
Table 2 Criteria to assess model fit

\begin{tabular}{c|rr|r|rr}
\hline \multicolumn{5}{c}{ Latent Classes } & \\
\hline \multirow{2}{*}{ Fit Index: } & $\mathbf{1}$ & $\mathbf{2}$ & $\mathbf{3}$ & $\mathbf{4}$ & $\mathbf{5}$ \\
\cline { 2 - 6 } G2 & 767.84 & 692.01 & 642.87 & 612.17 & 585.69 \\
df & 2036 & 2024 & 2012 & 2000 & 1988 \\
AIC & 789.84 & 738.01 & 712.87 & 706.17 & 703.69 \\
BIC & 826.34 & 814.33 & 829.00 & 862.12 & 899.46 \\
& & & & & \\
\hline
\end{tabular}

likely driven by higher probability of above-median harmful alcohol use (AUDIT) scores, experiences of violence, unprotected sex acts with paying partners, and being offered more money for sex without a condom. In addition, this group also exhibited very high financial risk. They were more likely to have belowmedian earnings, no savings, and at least some debt. In addition, they were more likely to have a high number of dependents and be the only wage earner for their households.

3. Class 3 exhibited low personal risk with mixed financial risk $(n=80 ; 39.2 \%)$. This group exhibited the lowest probability of having reported personal risks. This risk manifested as a low probability of the following variables: high AUDIT scores, previously experienced violence, high BSI scores, or a high number of unprotected vaginal sex acts for pay. However, despite such low personal risk, this group still exhibited some financial risk factors, including lack of savings. Furthermore, these participants did not exhibit a low probability of having more dependents, lower incomes, more debt, or more than one earner (all probability values between .48 and .57$)$.

\section{Differing Characteristics Across Latent Classes}

In the next stage of analysis, we examined whether or not variables that were excluded from the LCA demonstrated differences across identified classes. Table 4 shows that many of these variables differed between classes, lending support to the strength of the distinguished classes identified. For example, while analyses indicated that the classes did not differ by current age or the age of beginning sex work, we found evidence suggesting that the high personal risk with high financial risk class (Class 2) had been involved in sex work longer than the other two classes. Not surprisingly, we found evidence to suggest that the mixed personal risk with low financial risk group (Class 1) exhibited significantly higher incomes from sex work.

Additionally, the latent classes significantly differed on reported family social support. This was based on a one-way ANOVA of the total score on the Social Support scale, $F(1,201)=8.58, p<.001$. Follow-up Scheffe post hoc tests indicated that this was driven by decreased agreement within the high personal risk with high financial risk latent class (Class 2), compared to the mixed personal risk with low financial risk (Class 1), $p=.001$, and the low personal risk with mixed financial risk group (Class 3 ), $p=.021$. However, the mixed personal risk with low financial risk (Class 1) and the low personal risk with mixed financial risk group (Class 3) did not differ significantly $(p=.286)$.

Three additional count variables were tested for distinction between the latent classes. We found that the latent classes differed significantly in the number of participants who reported that sex work was their primary source of income $\chi^{2}(2)=11.66, n=204, p=$ .003. Follow-up chi-square analyses indicated that participants in the high personal risk with high financial risk class (Class 2) were significantly more likely to report that sex work was their primary source of income. This effect was primarily driven by the difference between the high personal risk class (Class 2 ) and the low personal risk class (Class 3). Similar chi-square analyses indicated that participants within Class 2 were also less likely to have a trust partner and more likely to report having been raped. Notably, with the exception of having sex work as one's primary source of income, none of these variables were included in the previously reported LCA. This further supports our hypothesis that the reported latent classes represent natural risk groupings in our sample.

The latent classes also differed on intention to use condoms in the future with a paying partner. This was based on a Kruskal-Wallis examination of Likert responses, $\chi^{2}=9.64, p=.008$. Follow-up Mann-Whitney $U$ tests indicated that this was driven by increased agreement within the low personal risk with mixed financial risk latent class (Class 3), compared to the high personal risk with high financial risk (Class 2), $p=.006$, and the mixed personal risk with low financial risk (Class 1 ), $p=.006$. However, the mixed personal risk with low financial risk (Class 1) and the high personal risk with high financial risk (Class 2) did not differ significantly with respect to the reported agreement. 
Table 3 Latent class prevalence and item response probabilities

\begin{tabular}{|c|c|c|c|}
\hline & $\begin{array}{c}\text { Low Financial } \\
\text { Risk }\end{array}$ & $\begin{array}{c}\text { High Risk } \\
\text { Overall }\end{array}$ & $\begin{array}{c}\text { Low } \\
\text { Personal } \\
\text { Risk }\end{array}$ \\
\hline Prevalence of latent class in sample & $20.6 \%$ & $40.2 \%$ & $39.2 \%$ \\
\hline Variables & Item R & ponse Probal & ties \\
\hline Alcohol use (AUDIT) & 0.267 & 0.803 & 0.289 \\
\hline Violence & 0.452 & 0.700 & 0.194 \\
\hline Depression (BSI) & 0.434 & 0.658 & 0.242 \\
\hline High unprotected sex acts & 0.835 & 0.739 & 0.017 \\
\hline Offered more money for unprotected sex & 0.684 & 0.666 & 0.294 \\
\hline Sex work as main income source & 0.888 & 0.943 & 0.793 \\
\hline One earner in household & 0.395 & 0.724 & 0.565 \\
\hline Debt & 0.232 & 0.714 & 0.515 \\
\hline No savings & 0.533 & 0.949 & 0.904 \\
\hline $2^{+}$Dependents & 0.170 & 0.457 & 0.478 \\
\hline Low income & 0.204 & 0.493 & 0.505 \\
\hline
\end{tabular}

Latent class prevalence and item response probabilities for the three-class model of risk. Dark gray boxes indicate high probability of group membership, while light gray boxes indicate low probability of group membership. Unhighlighted boxes are unlikely to drive class differentiation and are somewhere in the middle for the sample. Note that each variable significantly differed in frequency between the three latent classes, based on a series of chi-square analyses (all $p<.01$ )

\section{Discussion}

To our knowledge, this is the first study that has investigated the overlap and distinction between sexual/personal risk and financial risk factors among women engaged in sex work. These results provide data to support what the investigators believed based on anecdotal evidence: that risk in this population of sex workers is neither a unilateral scale nor a simple collection of separate constructs. Our findings suggest that risky behavior could manifest as three separate categories of women, with probabilistic combinations of sexual and financial risk. Due to our method of screening a high-risk population, we were unable to find evidence for a group that exhibited low risk for all variables. These types of women may have distinct needs in terms of support and advocacy for preventive and structural interventions. Identification of these typologies of populations at risk may facilitate better and more targeted interventions in the future.
Importantly, these results have expanded upon previous typology research and allay many concerns for this area of focus. Weitzer (2005) has suggested that, in practice, many important variables, such as violence, are not, or cannot be, adequately measured. One potential advantage of LCA is the ability to omit variables and still assign a participant to a latent risk group, based on remaining variables. This could allow a field worker to employ our findings without making rigorous and precise measurements. Furthermore, all variables presented above have been dichotomized in order to make them more versatile for field researchers.

In addition, this study represents a movement away from location-based risk categories and could serve as a template for future risk research. Directly measuring risk variables and categorizing participants into real-world types could represent a welcome addition to the field. The current findings also open up new ways to classify risk change over time in the way that Seib, Dunne, Fischer, and Najman (2010) have done. In fact, we believe that Seib et al. could 
Fig. 2 Three latent classes of risk behavior

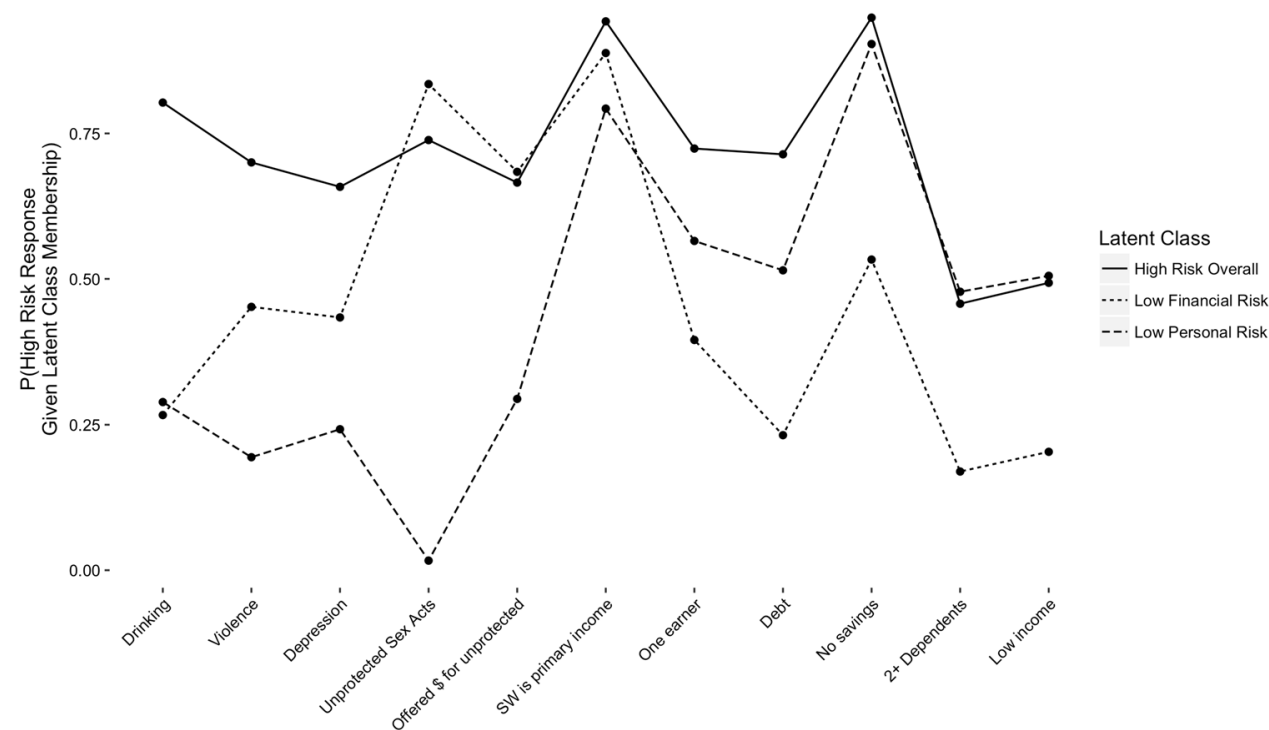

Table 4 Differences between the latent classes, with respect to count variables of interest, most that were excluded from the original LCA

\begin{tabular}{|c|c|c|c|c|}
\hline Variable & $\begin{array}{l}\text { Low financial risk } \\
n=42\end{array}$ & $\begin{array}{l}\text { High risk overall } \\
n=82\end{array}$ & $\begin{array}{l}\text { Low personal risk } \\
n=80\end{array}$ & $p$ value \\
\hline \multicolumn{5}{|l|}{ Latent class } \\
\hline Current age (in years) & $33.48(9.70)$ & $36.44(9.15)$ & $35.74(9.35)$ & ns \\
\hline Age when began sex work (in years) & $27.60(8.73)$ & $29.08(8.35)$ & $30.05(8.53)$ & ns \\
\hline Years of sex work & $5.75(6.39)$ & $\mathbf{7 . 0 8}(5.34)^{\mathrm{a}}$ & $5.54(4.66)$ & $p^{\mathrm{b}}=.046$ \\
\hline Income from sex work (in $100 \mathrm{k}$ tugriks) & $720(768)^{\mathrm{c}}$ & $388(351)$ & $373(505)$ & $p^{\mathrm{b}}<.001$ \\
\hline Social support & $58.41(12.52)$ & $47.04(15.64)^{\mathrm{c}}$ & $53.79(16.13)$ & $p<.001$ \\
\hline Sex work is not primary income & $11.9 \%{ }^{\mathrm{d}}$ & $4.9 \%$ & $20.0 \%$ & $p=.013$ \\
\hline No intimate partner & $38.1 \%$ & $63.4 \%$ & $37.5 \%$ & $p=.002$ \\
\hline Has been forced into sex & $14.3 \%$ & $34.1 \%$ & $15.0 \%$ & $p=.005$ \\
\hline Intends to use condom with future paying partner & $2.86(.78)$ & $2.78(1.00)$ & $3.33(.73)$ & $p=.008$ \\
\hline
\end{tabular}

Significantly different groups highlighted in bold. Top six rows focus on continuous variables, where all p values were calculated by using a one-way ANOVA. Values tagged a $\left({ }^{\mathrm{a}}\right)$ significantly differed from non-bold classes via post hoc LSD tests. The $\left(^{\mathrm{b}}\right)$ symbol indicates that the data were logtransformed before computing significance, in order to normalize the data. Values tagged with a $\left({ }^{c}\right)$ symbol were significantly different via Scheffe post hoc tests. Middle three rows focus on categorical variables, where significance was determined by using chi-square tests. Follow-up chi-square tests used to isolate which class was driving overall the significant difference (all $p s<.05$, unless noted by $\left({ }^{\mathrm{d}}\right.$ ) symbol, which did not differ). Bottom row focuses on a Likert variable, where significance was determined with a Kruskal-Wallis nonparametric test. Follow-up Mann-Whitney U tests were used to determine exactly which latent class was significantly different (all $p s<.01$ )

break their sample into latent classes and measure changes within specific risk types over time.

Furthermore, our findings provoke an important dialogue about how best to target different preventive needs among women engaged in sex work. As a large and globally located population, women engaged in sex work continue to be at highest risk for HIV. Therefore, they warrant additional attention and consideration in terms of targeted responses for risk reduction. Our data suggest that levels of personal and financial risk may vary across latent classes of women. Future research could examine how women in different risk classes will respond to interventions that are designed to reduce risky behavior. Previous research has been largely limited by the desire to use a single, effective intervention for all participants meeting the inclusion criteria. For instance, one recent study showed that a microfinance intervention significantly reduced instances of unprotected sex, along with the number of paying sexual partners (Witte et al., 
2015). In light of our LCA, we hypothesize that women with different risk profiles will differentially respond to this intervention and other interventions.

In particular, we note that the mixed personal risk with low financial risk group (Class 1) also exhibited higher numbers of unprotected vaginal sex acts. We believe that women at low financial risk may be more likely to respond to microfinance interventions targeting HIV prevention. Although we lacked the sample size to test these hypotheses with our existing dataset, future studies may be able to design more targeted and effective interventions. In turn, better targeting could save resources and allow researchers to develop more effective strategies for women who are not likely to respond to existing interventions.

Finally, our results further elucidate our understanding of risky behavior within a high-risk population. This information could be used to develop interventions that are more informed of the interplay between personal and financial risk. Currently, interventions are being developed that are designed to integrate HIV prevention with both violence prevention and substance abuse. Our results indicate that the different risk pools will be heterogeneously distributed throughout the population. Furthermore, researchers may be able to use those heterogeneities to engineer a better, more targeted intervention. Conversely, combining interventions in order to strategically target different types of risk may allow for a more effective outcome.

\section{Limitations}

Findings should be considered in light of study limitations. These data were from a baseline assessment of an intervention trial wherein we screened women for sexual risk (non-condom use with paying partners) and their relative interest in learning more about alternative ways in which to earn income. The sample for the LCA was not representative of all women engaging in sex work in Mongolia. However, this limitation could arguably make our analysis more relevant for future interventions that are aiming to work with similar populations.

\section{Conclusions}

Increased understanding of the comorbid sexual risk, personal, and financial issues facing women who engage in sex work require us to be far more innovative in our prevention approaches. Many prevention programs exist for women engaged in sex work. However, identifying categories of risk among women engaged in sex work could help practitioners and researchers to more efficiently identify targets for future interventions. Furthermore, these risk categories could explain heterogeneous responses to existing interventions. For this reason, we recommend the use of LCA in future research studies in order to better target interventions for this heterogeneous group of women.

Acknowledgments This study was made possible by Grant R34MH0 93227-02 to PI Susan S. Witte from the National Institute of Mental Health.

\section{References}

Aidala, A., Cross, J. E., Stall, R., Harre, D., \& Sumartojo, E. (2005). Housing status and HIV risk behaviors: Implications for prevention and policy. AIDS and Behavior, 9, 251-265.

Baral, S., Beyrer, C., Muessig, K., Poteat, T., Wirtz, A. L., Decker, M. R., \& Kerrigan, D. (2012). Burden of HIV among female sex workers in low income and middle income countries: A systematic review and meta analysis. Lancet Infectious Disease, 12, 538-549.

Baral, S., Todd, C. S., Aumakhan, B., Lloyd, J., Delegchoimbol, A., \& Sabin, K. (2013). Literature review of HIV among female sex workers in the Central Asian Republics, Afghanistan, and Mongolia: Contexts and convergence with drug use. Drug and Alcohol Dependence, 132, S13-S16.

Beyrer, C., Crago, A. L., Bekker, L. G., Butler, J., Shannon, K., Kerrigan, D., \& Strathdee, S. A. (2015). An action agenda for HIV and sex workers. Lancet, 385, 287-301.

Buzdugan, R., Halli, S. S., \& Cowan, F. M. (2009). The female sex work typology in India in the context of HIV/AIDS. Tropical Medicine \& International Health, 14, 673-687.

Carlson, C. E., Chen, J., Chang, M., Batsukh, A., Toivgo, A., Riedel, M., \& Witte, S. S. (2012). Reducing intimate and paying partner violence against women who exchange sex in Mongolia: Results from a randomized clinical trial. Journal of Interpersonal Violence, 27, 1911-1931.

Carlson, C.E., Tsai, L. C., Aira, T., Riedel, M., \& Witte, S. S. (2014). Risk and resilience among women who engage in sex work in Mongolia. In M. McLelland \& V.Mackie(Eds.), Routledge handbook of sexuality studies in East Asia (pp. 305-315). London: Routledge.

Carlson, C. E., Witte, S. S., Norcini Pala, A., Tsai, L. C., Wainberg, M., \& Aira, T. (2016). The impact of violence, perceived stigma, and other work-related stressors on depressive symptoms among women engaged in sex work. Manuscript submitted for publication.

Clogg, C. (1995). Latent class models. In G. Arminger, C. Clogg, \& M. Sobel (Eds.), Handbook of statistical modeling for the social and behavioral sciences (pp. 311-359). New York: Plenum Press.

Deering, K. N., Amin, A., Shoveller, J., Nesbitt, A., Garcia-Moreno, C., Duff, P., \& Shannon, K. (2014). A systematic review of the correlates of violence against sex workers. American Journal of Public Health, 104, E42-E54.

Derogatis, L. R. (1993). BSI brief symptom inventory: Administration, scoring, and procedures manual. Minneapolis, MN: National Computer Systems.

Fisher, J. C., Bang, H., \& Kapiga, S. H. (2007). The association between HIV infection and alcohol use: A systematic review and meta-analysis of African studies. Sexually Transmitted Diseases, 34, 856-863.

Gu, J., Lau, J. T., Chen, H., Chen, X., Liu, C., \& Liu, J. (2010). Mental health and interpersonal factors associated with HIV-related risk behaviors among non-institutionalized female injection drug users who are also sex workers in China. Women and Health, 50, 20-36.

Hagan, J. E., \& Dulmaa, N. (2007). Risk factors and prevalence of HIV and sexually transmitted infections among low-income female commercial sex workers in Mongolia. Sexually Transmitted Diseases, 34, 83-87.

Harcourt, C., \& Donovan, B. (2005). The many faces of sex work. Sexually Transmitted Infections, 81, 201-206.

Kalichman, S. C., Simbayi,L. C., Kaufman, M., Cain, D., \& Jooste, S. (2007). Alcohol use and sexual risks for HIV/AIDS in sub-Saharan Africa: Systematic review of empirical findings. Prevention Science, 8, 141151.

Karandikar, S., \& Prospero, M. (2010). From client to pimp male violence against female sex workers. Journal of Interpersonal Violence, 25, 257 273.

Kerrigan, D., Wirtz, A., Baral, S., Stanciole, A., Butler, J., Oelrichs, R., \& Beyer, C. (2013). The global HIV epidemics among sex workers. Washington, DC: World Bank Publications.

Lanza, S. T., Collins, L. M., Lemmon, D., \& Schafer, J. L. (2007). PROC LCA: A SAS procedure for latent class analysis. Structural Equation Modeling, 14, 671-694. 
Li, Q., Li, X., \& Stanton, B. (2010). Alcohol use among female sex workers and male clients: An integrative review of global literature. Alcohol and Alcoholism, 45, 188-199.

Lynskey, M. T., Agrawal, A., Bucholz, K. K., Nelson, E. C., Madden, P. A., Todorov, A. A., \& Heath, A. C. (2006). Subtypes of illicit drug users: A latent class analysis of data from an Australian twin sample. Twin Research and Human Genetics, 9, 523-530.

McCarthy, B., Benoit, C., \& Jansson, M. (2014). Sex work: A comparative study. Archives of Sexual Behavior, 43, 1379-1390.

McCutcheon, A. (1987). Latent class analysis. Beverly Hills, CA: Sage Publications.

Nemoto, T., Bodeker, B., \& Iwamoto, M. (2011). Social support, exposure to violence and transphobia, and correlates of depression among male-tofemale transgender women with a history of sex work. American Journal of Public Health, 101, 1980-1988.

Nixon, K., Tutty,L., Downe, P., Gorkoff, K., \& Ursel, J. (2002). The everyday occurrence: Violence in the lives of girls exploited through prostitution. Violence Against Women, 8, 1016-1043.

Odek, W., Busza, J., Morris, C., Cleland, J., Ngugi, E., \& Ferguson, A. (2009). Effects of micro-enterprise services on HIV risk behavior among female sex workers in Kenya's urban slums. AIDS and Behavior, 13, 449-461.

Open Society Institute. (2009). Arrest the violence: Human rights abuses against sex workers in Central and Eastern Europe and Central Asia. Budapest, Hungary: Sex Workers' Rights Advocacy Network.

Oyunbileg, S., Sumberzul, N., Udval, N., Wang, J. D., \& Janes, C. R. (2009). Prevalence and risk factors of domestic violence among Mongolian women. Journal of Women's Health, 18, 1873-1880.

Parcesepe, A., Aira, T., Chang, M., Riedel, M., Carlson, C., DiBennardo, R., \& Witte, S. S. (2015). Physical and sexual violence, childhood sexual abuse and HIV/STI risk behavior among alcohol-using women engaged in sex work in Mongolia. Global Public Health, 10, 88-102.

Peterson, J. A., Reisinger, H. S., Schwartz, R. P., Mitchell, S. G., Kelly, S. M., Brown, B. S., \& Agar, M. H. (2008). Targeted sampling in drug abuse research: A review and case study. Field Methods, 20, 155-170.

Puradiredja, D. I., \& Coast, E. (2012). Transactional sex risk across a typology of rural and urban female sex workers in Indonesia: A mixed methods study. PLoS ONE, 7, e52858.

Reed, E., Gupta, J., Biradavolu, M., Devireddy, V., \& Blankenship, K. M. (2010). The context of economic insecurity and its relation to violence and risk factors for HIV among female sex workers in Andhra Pradesh, India. Public Health Reports, 4, 81-89.

Rhodes, T., Simic, M., Baros, S., Platt, L., \& Zikic, B. (2008). Police violence and sexual risk among female and transvestite sex workers in Serbia: Qualitative study. British Medical Journal, 337, 560-563.

Saunders, J. B., Aasland, O. G., Babor, T. F., de la Fuente, J. R., \& Grant, M. (1993). Development of the Alcohol Use Disorders Identification Test (AUDIT): WHO collaborative project on early detection of persons with harmful alcohol consumption II. Addiction, 88, 791-804.

Seib, C., Dunne, M. P., Fischer, J., \& Najman, J. M. (2010). Commercial sexual practices before and after legalization in Australia. Archives of Sexual Behavior, 39, 979-989.

Shahmanesh, M., Patel, V., Mabey, D., \& Cowan, F. (2008). Effectiveness of interventions for the prevention of HIV and other sexually transmitted infections in female sex workers in resource poor setting: A systematic review. Tropical Medicine \& International Health, 13, 659-679.

Sherman, S. G., Srikrishnan, A. K., Rivett, K. A., Liu, S. H., Solomon, S., \& Celentano,D.D. (2010). Acceptability of a microenterprise intervention among female sex workers in Chennai, India. AIDS and Behavior, 14, 649-657.

Shuper, P. A., Neuman, M., Kanteres, F., Baliunas, D., Joharchi, N., \& Rehm, J. (2010). Causal considerations on alcohol and HIV/AIDS-a systematic review. Alcohol and Alcoholism, 45, 159-166.

Stratford, D., Mizuno, Y., Williams, K., Courtenay-Quirk, C., \& O’Leary, A. (2008). Addressing poverty as risk for disease: Recommendations from CDC's consultation on microenterprise as HIV prevention. Public Health Reports, 123, 9-20.

Straus, M. A., Hamby, S. L., Boney-McCoy, S., \& Sugarman, D. B. (1996). The Revised Conflict Tactics Scales (CTS2): Development and preliminary psychometric data. Journal of Family Issues, 17, 283-316.

Tsai, L. C., Witte, S. S., Aira, T., Riedel, M., Offringa, R., \& Chang, M. (2015). Efficacy of a microsavings intervention in increasing income and reducing economic dependence upon sex work among women in Mongolia. International Social Work. doi:10.1177/002087281559 4866.

UNICEF. (2006). Country report: Mongolia. Ulaanbaatar: United Nations Children's Fund.

van Griensven, G. J., Limanonda, B., Chongwatana, N., Tirasawat, P., \& Coutinho, R. A. (1995). Socio-economic and demographic characteristics and HIV-1 infection among female commercial sex workers in Thailand. AIDS Care, 7, 557-565.

Weitzer, R. (2005). Flawed theory and method in studies of prostitution. Violence Against Women, 11, 934-949.

WHO. (2011). Management of substance abuse: Mongolia Country Profile 2011. Geneva: World Health Organization.

Witte, S. S., Aira, T., Tsai, L. C., Riedel, M., Offringa, R., Chang, M., \& ElBassel, N. (2015). Efficacy of a savings-led microfinance intervention to reduce sexual risk for HIV among women engaged in sex work: A randomized clinical trial. American Journal of Public Health, 105, e92102. doi:10.2105/AJPH.2014.302291.

Witte, S. S., Altantsetseg, B., Aira, T., Riedel, M., Chen, J., Potocnik, K., \& Yao, H. (2011). Reducing sexual HIV/STI risk and harmful alcohol use among female sex workers in Mongolia: A randomized clinical trial. AIDS and Behavior, 15, 1785-1794.

Witte, S. S., Batsukh, A., \& Chang, M. (2010). Sexual risk behaviors, alcohol abuse and intimate partner violence among sex workers in Mongolia: Implications for HIV prevention intervention development. Journal of Prevention and Intervention in the Community, 38, 89-103.

Yang, C., Latkin, C., Luan, R., \& Nelson, K. (2010). Condom use with female sex workers among male clients in Sichuan Province, China: The role of interpersonal and venue-level factors. Journal of Urban Health, 87, 292-303.

Yuen, W. W., Tran, L., Wong, C. K., Holroyd, E., Tang, C. S., \& Wong, W.C. (2016). Psychological health and HIV transmission among female sex workers: A systematic review and meta-analysis. AIDS Care, 28, 816824.

Zhang, C., Li, X., Chen, Y., Hong, Y., Shan, Q., Liu, W., \& Zhou, Y. (2014). Alcohol and other drug use, partner violence, and mental health problems among female sex workers in Southwest China. Health Care for Women International, 35, 60-73.

Zimet, G. D., Dahlem, N. W., Zimet, S. G., \& Farley, G. K. (1988). The Multidimensional Scale of Perceived Social Support. Journal of Personality Assessment, 52, 30-41. 